\title{
A note on daily movement patterns of a female Asiatic black bear (Ursus thibetanus) in a suburban area of Iwate Prefecture, northeastern Japan
}

\author{
Yoshihiro Sakamoto,*, Takashi Kunisaki ${ }^{1}$, Isao Sawaguchi ${ }^{2}$, Toshiki Aoi ${ }^{2}$, Koji Harashina ${ }^{2}$ \\ and Yoshitaka Deguchi ${ }^{2} * *$
}

${ }^{1}$ Graduate School of Agriculture, Iwate University, Morioka, Iwate 020-8550, Japan

${ }^{2}$ Faculty of Agriculture, Iwate University, Morioka, Iwate 020-8550, Japan

As urban areas sprawl and natural environments are modified, human-bear conflicts are becoming increasingly more common and significant management concerns throughout the United States (Peine 2001; Beckmann and Lackey 2008) and other countries (Mattson 1990; Huygens et al. 2004; Sangay and Vernes 2008). In North America, nuisance activities by American black bears (Ursus americanus) include raiding crops and orchards, feeding on human food and garbage, and attacking livestock and humans (Herrero 2002). However, management policies for black bears vary according to the status of the species, which ranges from pest to threatened (Pelton 2003).

American black bears are generally crepuscular but may shift to diurnal or nocturnal activities depending on human activity (Pelton 2003). Several studies have reported such behavioral changes of black bears in British Columbia (Reimchen 1998), Nevada (Beckmann and Berger 2003), and California (Ayres et al. 1986; Lyons 2005; Matthews et al. 2006).

Recently, crop damage and human injuries have also been caused by Asiatic black bears ( $U$. thibetanus) in Japan (Hazumi 1994). Most of these disturbances occur in suburban landscapes surrounded by forests and farmlands with obscure boundaries (Ozaki and Kudo 2002). In Japan, only a few behavioral studies have addressed such problems with black bears. In Nagano Prefecture, central Japan, Huygens and Hayashi (1999) constructed an electric fence around corn fields to test its effect on crop depredation by black bears. In the Experimental Farm of Tohoku University, northeastern Japan, Deguchi et al. (2003) placed infrared cameras near a corn field to observe nuisance behavior by black bears.
Despite these studies, little is known of the movement patterns of Asiatic black bears in suburban areas of Japan. Detailed monitoring of active Asiatic black bears near suburban areas is required to reduce human-bear interactions. Therefore, to characterize bear movement and resource selection patterns during the crop harvest season, we monitored the movement of a female Asiatic black bear, which was tagged in a forest adjacent to a suburban area, using global positioning system (GPS) technology.

\section{Study area}

The study was conducted over approximately 1000 ha on the outskirts of Morioka $\left(39^{\circ} 42^{\prime} \mathrm{N}, 141^{\circ} 09^{\prime} \mathrm{E}\right)$, Iwate Prefecture, northeastern Japan (Fig. 1). This area is located in the cool temperate zone; the mean annual temperature is $10.2^{\circ} \mathrm{C}$, and annual precipitation is 1142.5 mm (Japan Meteorological Agency 2007). The elevation of the area ranges from approximately $150 \mathrm{~m}$ to $865.5 \mathrm{~m}$ at the peak of Mt. Hakogamori along the eastern edge of the Ou Mountains (Fig. 1). The primary vegetation consists of secondary forests dominated by Mongolian oak (Quercus mongolica var. grosseserrata), Japanese white oak ( $Q$. serrata), plantations of Japanese cedar (Cryptomeria japonica), Japanese red pine (Pinus densiflora), and Japanese larch (Larix kaempferi). Natural forests of Japanese beech (Fagus crenata) also present, but are sparse above $500 \mathrm{~m}$.

A mosaic of residential areas and agricultural fields is interspersed among the forested mountains. Most of the agricultural fields are occupied by apple (Malus pumila var. domestica) orchards, which are harvested from 

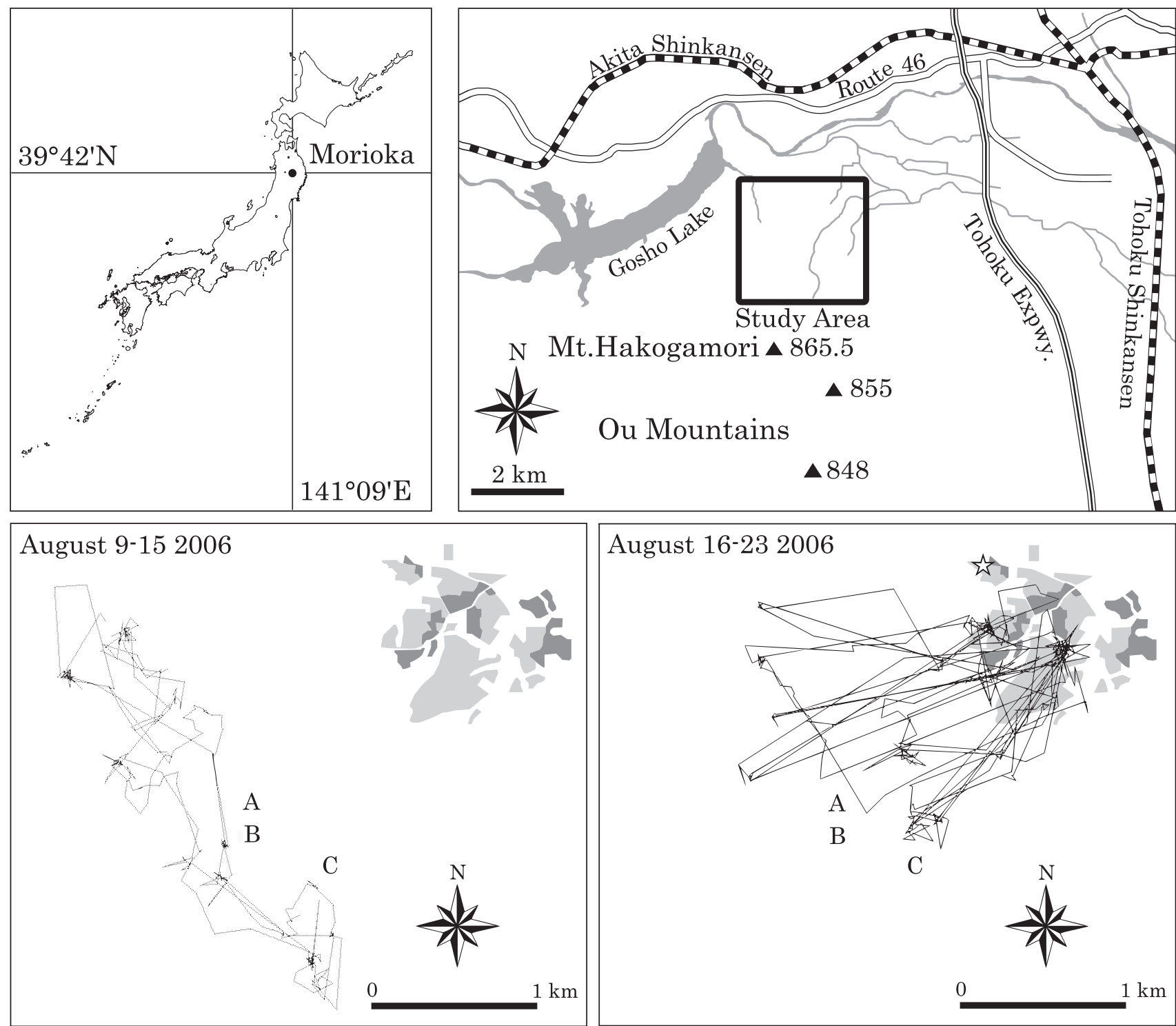

Fig. 1. Location of study area and movement patterns of a female Asiatic black bear at the outskirts of Morioka, northeastern Japan. Dotted and straight lines denote travel route of the bear in the first half (Aug. 9-15 2006) and the second half (Aug. 16-23 2006). Alphabets (A-C), star, light and dark gray polygons represent set points of barrel traps, recovery point of the GPS collar, agricultural fields and residential areas, respectively.

mid-August to November. In contrast, Japanese pear (Pyrus pyrifolia var. culta), grape (Vitis spp.), and plum (Prunus spp.) orchards, paddy fields, and vegetable gardens are few and negligible (Nagasaka, M. personal communication). Since the 1980 s, the agricultural crops in this area have been frequently damaged by black bears during the summer and autumn. The local government has received several complaints from residents and has conducted nuisance control of black bears $(n=27)$ during the summers of 1999-2008 (Iwate Prefecture unpublished data). Despite these efforts, crop depredation has continued in this area. Particularly severe crop damage occurred from June to November 2006, which resulted in many nuisance black bears $(n=13)$ being exterminated (Tsujimoto, T. personal communication).

\section{Methods}

From 30 July to 8 August 2006, three barrel traps baited with honey (Mano et al. 1990) were set in a mountainous habitat approximately $1.5 \mathrm{~km}$ from the village of Morioka (Fig. 1). The traps were checked every 2 days. To immobilize the trapped bear, a mixture of ketamine hydrochloride $(4.6 \mathrm{mg} / \mathrm{kg})$ and medetomidine hydrochlo- 
ride $(46.3 \mu \mathrm{g} / \mathrm{kg})$ was used to anesthetize the bear, and hydrochloric atipamezole $(231.5 \mu \mathrm{g} / \mathrm{kg})$ was used as an antagonist. A GPS collar equipped with an activity sensor and drop-off device (285 g; GPS_3300S; Lotek Wireless Inc., Ontario, Canada), which totaled less than $5 \%$ of the animal's body weight (see Aldridge and Brigham 1988), was fitted on the bear. The bear was marked with a numbered plastic tag, and its age was roughly categorized as yearling or adult based on body condition (Tsujimoto, T. personal communication).

To avoid aversive behavior due to capture and handling (Clark et al. 2002), we handled and released the bear with minimum disturbance (Beckmann et al. 2004). For the first 24 hours after the bear was released, movement data were excluded from the analysis to account for the anesthetics.

We determined the locations of the bear using GPS technology; triangulations were unnecessary. Following data collection, we approached the bear by homing (White and Garrot 1990) and retrieved the collar using the remote-controlled drop-off device.

GPS location fixes were assessed at 10-minute intervals. An activity sensor stored the number of vertical and horizontal movements of the bear every 5 minutes. The 5-minute activity counts ( $n$ ) were summed and divided into active $(n>14)$ and inactive $(n \leq 13)$ periods (Kozakai et al. 2008). The hourly activity rate (\%) was also analyzed.

Each GPS fix was determined using a three-dimensional fix, a two-dimensional fix, and a dilution of precision (DOP), which measures the quality of satellite geometry (e.g., Moen et al. 1997). Lewis et al. (2007) recommended excluding two-dimensional fixes with DOP $>5$ to remove conspicuous fix errors and to retain the accuracy within $100 \mathrm{~m}$; we followed these criteria.

Animal Movement version 2.04 beta (Hooge and Eichenlaub 2001) for $\mathrm{ArcView}^{\circledR}$ GIS version 3.2a (ESRI Inc., California, USA) was used to analyze the movements and habitat selection of the bear. We used $90 \%$ kernel density estimation (KDE) with least-squares crossvalidation (Worton 1989; Seaman and Powell 1996; Seaman et al. 1999; Börger et al. 2006) to define the bear distribution. Fix locations were evaluated over four 6-hour periods (0000-0559, 0600-1159, 1200-1759, and 1800-2359), following calculated daylight hours (Hydrographic and Oceanographic Department 2006) and field observations during the sampling period. A digitized 1:25,000 vegetation map (Biodiversity Center of Japan 2006) was used to characterize the vegetation types used by the bear. Vegetation categories were reclassified as secondary deciduous forests, conifer plantations, grasslands, agricultural fields and residential areas, and the fix locations within each vegetation category were calculated. Chi-squared tests for independence ( $\mathrm{R}$ version 2.8.0; $\mathrm{R}$ Development Core Team 2008) were used to test for differences in fix locations and habitat selection by the bear over each 6-hour period. The significance level was set at $\alpha=0.01$. We also surveyed the agricultural fields and conducted interviews with local farmers $(n=7)$ to determine the times of day during which humans were most often in the fields.

\section{Results}

On 6 August 2006, a female Asiatic black bear (54 kg) was captured in the secondary deciduous forest (capture site A; Fig. 1) and was released 2 days later. The presence of cubs was not detected, although the bear was classified as an adult based on the developed dugs. We also collected scat from the barrel trap, but no agricultural crops were included therein. From 9 to 23 August of the sampling period, the rate of successful GPS fixes was $33.9 \%(n=695)$, the average DOP was $4.2(S E=$ 0.12 ), and the activity sensor recorded 1401 counts. When the collar was retrieved on 25 August, we observed that the bear had damaged Japanese pears in a kitchen garden (Fig. 1).

Throughout the sampling period, the $90 \% \mathrm{KDE}$ of the bear was 309.0 ha. Habitat selection by the bear differed significantly between the periods of 9-15 August and 16-23 August. During the first 7 days, the bear only moved throughout mountainous habitat, whereas during the latter 8 days, the bear approached agricultural fields and residential areas (first half $\chi^{2}=69.79, d f=6$, $P<0.001$; second half $\chi^{2}=184.05, d f=6, P<0.001$; Table 1). Furthermore, the bear tended to prefer mountainous habitat ( $n=55$ and 109) during the day and primarily moved around the village $(n=82$ and 43) at night (Table 1, Fig. 1).

Similarly, activity time also significantly differed between these two periods (Fig. 2). During the first 7 days, activity rates were higher from 1400 to $1900 \mathrm{~h}$, with peaks at 1400,1600,1700, and $1900 \mathrm{~h}$, and lower ( $\leq 45 \%$ ) from 2000 to $1100 \mathrm{~h}$ (Fig. 2). In contrast, during the latter period, the activity rate was highest from late at night to early in the morning. The activity rate peaked at 1900, 2000, 0100, 0500, and $0900 \mathrm{~h}$, and was lower (<40\%) from 1100 to $1700 \mathrm{~h}$ (Fig. 2). 
Table 1. The relationships between GPS fix locations and habitat type selection by a female Asiatic black bear at the outskirts of Morioka, northeastern Japan, from 9 to 23 August 2006. Each value represents the observed frequency, while values in parenthesis indicates the expected frequency.

\begin{tabular}{|c|c|c|c|c|c|c|c|}
\hline & & \multirow[b]{2}{*}{ Number of fix* } & \multicolumn{5}{|c|}{ Habitat type } \\
\hline \multicolumn{2}{|c|}{ Tracking period } & & $\begin{array}{c}\text { Secondary } \\
\text { deciduous forests }\end{array}$ & $\begin{array}{c}\text { Conifer } \\
\text { plantations }\end{array}$ & Glasslands & $\begin{array}{l}\text { Agricultural } \\
\text { fields }\end{array}$ & $\begin{array}{l}\text { Residential } \\
\text { areas }\end{array}$ \\
\hline \multirow[t]{4}{*}{ 9-15 August } & 0000-0559 & 98 & $70(62)$ & $27(24)$ & $1(12)$ & - & - \\
\hline & 0600-1159 & 53 & $28(33)$ & $23(13)$ & $2(7)$ & - & - \\
\hline & $1200-1759$ & 91 & $45(58)$ & $15(22)$ & $31(11)$ & - & - \\
\hline & $1800-2359$ & 65 & $51(41)$ & $10(16)$ & $4(8)$ & - & - \\
\hline \multirow[t]{4}{*}{ 16-23 August** } & 0000-0559 & 122 & $-(41)$ & $40(37)$ & - & $80(39)$ & 2 \\
\hline & 0600-1159 & 55 & $35(19)$ & $19(16)$ & 1 & $-(18)$ & - \\
\hline & $1200-1759$ & 109 & $64(37)$ & $39(33)$ & 6 & $-(35)$ & - \\
\hline & $1800-2359$ & 76 & $23(26)$ & $10(23)$ & - & $36(24)$ & 7 \\
\hline
\end{tabular}

*The GPS fix locations not included within each 90\% KDE were excluded (9-15 August, $n=2,2,1$ and $0 ; 16-23$ August, $n=17,2,0$ and 2).

**Because expected frequency was negligible, the GPS fix locations of Grasslands nad Residential areas were excluded when the test was evaluated.

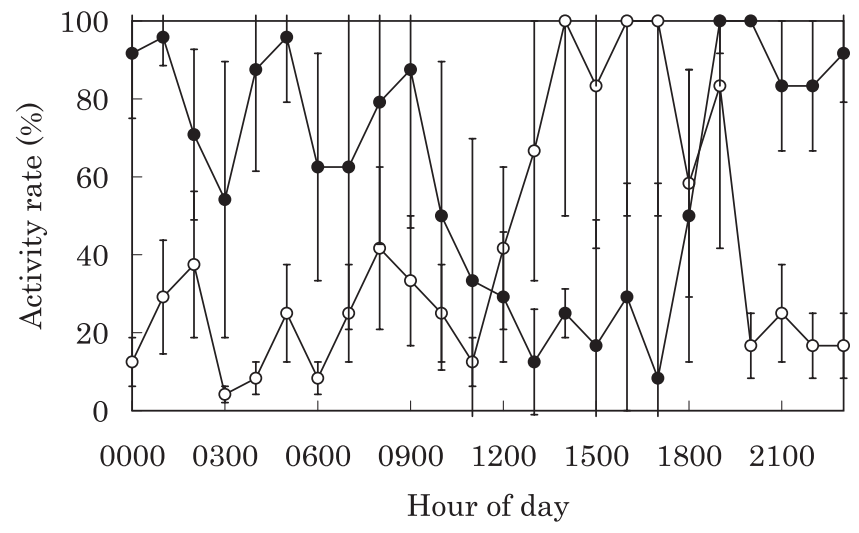

Fig. 2. Activity profile of a female Asiatic black bear at the outskirts of Morioka, northeastern Japan, from 9 to 23 August 2006. Open circles represent data points from the first half ( 9 to 15 August), and closed circles represent data points from the second half (16 to 23 August) of the study. Each circle represents the median of the activity rate $(\%)$ per hour. The vertical bars represent the semi inter-quartile range.

All farmers began their workday in the orchards between 0800 and $0830 \mathrm{~h}$ and finished between 1700 and $1800 \mathrm{~h}$; they were continuously present throughout these periods.

On 15 August 2007, the same female black bear was captured by local hunters in an orchard within the study area and was killed for bear nuisance control. At the same time, the hunters witnessed a cub fleeing from the site of capture (Tsujimoto, T. personal communication).

\section{Discussion}

Bacon and Burghardt (1976) and Larivière et al. (1994) argued that diurnal patterns of bears can be explained by foraging behavior. During the first half of the monitoring period, the female black bear only moved within the mountainous forests in the daytime, even though bears can easily invade the village and bear depredation actually occurred during this same period. Diurnal activity of this female may have been influenced by exclusive competition from other bears (e.g., adult male bears; Matthew et al. 2006) or ample food resources in the mountain habitats, especially secondary deciduous forests.

The movement of this bear was likely not affected by a relationship between capture and/or handling and avoidance of the village, because she was active within the mountain forests around the capture site during the first 7 days. However, Cattet et al. (2008) indicated that capture and handling affected the daily movement rates of collared grizzly bears (U. arctos) and American black bears for relatively long periods of time ( $\geq 1$ month). Future studies should examine whether capture and handling affects the movement patterns of collared bears, promoting nocturnal and/or nuisance activity instead of inherent crepuscular or diurnal activity (Reimchen 1998; Pelton 2003).

Conversely, during the second half of the survey period, this female black bear shifted her distribution and activity patterns quite rapidly before and after moving 
toward the village, where nuisance behavior was likely greater. These results indicate that this female was intentionally avoiding contact with humans, similar to previous studies (Ayres et al. 1986; Reimchen 1998; Beckmann and Berger 2003; Lyons 2005; Matthews et al. 2006). Ayres et al. (1986) and Matthews et al. (2006) also reported that female American black bears can shift their activity patterns within a few days and across seasons. We suggest that such behavioral changes of black bears occur quite quickly, and further studies of this phenomenon are warranted.

Here, we described the daily movement patterns of a female Asiatic black bear in a suburban area of Japan. Together with other investigations at nearby sites (Huygens and Hayashi 1999; Deguchi et al. 2003), our approach using GPS technology may prove useful for developing management policies for nuisance black bears. However, our tracking period was brief, and bears must be collared in advance, especially if daily bear movement rates are evaluated more strictly (Cattet et al. 2008). In future studies, simultaneous monitoring using GPS technology will be crucial for revealing social interactions among black bears. Such results would not only be useful for developing defensive measures but also for conserving mountains and forests as bear habitat.

Acknowledgments: This study was funded in part by a Grant-in-Aid for Scientific Research (No. 17380086) from the Japan Society for the Promotion of Science. We thank gratefully H. Higashi, H. Takahashi and M. Nagasaka for their help with the study design and discussion. T. Tsujimoto assisted with veterinary techniques. K. Waseda and M. Murakami assisted with maintenance of instruments. T. Kikuchi assisted with bear capture techniques. Y. Hirano, K. Yanagisawa, M. Saito, N. Taura and E. Hirabayashi aided in bear handling. Dr. K. Kaji and H. Iwaki assisted in the habitat analysis. Finally, we thank Dr. G. A. Feldhamer, Y. Umemura, U. Sakamoto and three anonymous reviewers for valuable comments on the manuscript.

\section{References}

Aldridge, H. D. J. N. and Brigham, R. M. 1988. Load carrying and maneuverability in an insectivorous bat: a test of the 5\% "rule" of radiotelemetry. Journal of Mammalogy 69: 379-382.

Ayres, L. A., Chow, L. S. and Graber, D. M. 1986. Black bear activity patterns and human induced modifications in Sequoia National Park. International Conference on Bear Research and Management 6: 151-154.
Bacon, E. S. and Burghardt, G. M. 1976. Ingestive behaviors of the American black bear. International Conference on Bear Research and Management 3: 13-25.

Beckmann, J. P. and Berger, J. 2003. Rapid ecological and behavioral changes in carnivores: the responses of black bears (Ursus americanus) to altered food. Journal of Zoology 261: 207-212.

Beckmann, J. P., Lackey, C. W. and Berger, J. 2004. Evaluation of deterrent techniques and dogs to alter behavior of "nuisance" black bears. Wildlife Society Bulletin 32: 1141-1146.

Beckmann, J. P. and Lackey, C. W. 2008. Carnivores, urban landscapes, and longitudinal studies: a case history of black bears. Human-Wildlife Conflicts 2: 168-174.

Biodiversity Center of Japan 2006. Vegetation Survey: 6th and 7th National Survey on the Natural Environment. Nature Conservation Bureau, Ministry of the Environment, Fujiyoshida, Yamanashi (in Japanese). <http://www.vegetation.jp/miru/5941/index.html>. Accessed 2008 Mar 2.

Börger, L., Franconi, N., de Michele, G., Gantz, A., Meschi, F., Manica, A., Lovari, S. and Coulson, T. 2006. Effects of sampling regime on the mean and variance of home range size estimates. Journal of Animal Ecology 75: 1393-1405.

Cattet, M., Boulanger, J., Stenhouse, G., Powell, R. A. and PeynoldsHogland, M. J. 2008. An evaluation of long-term capture effects in ursids: implications for wildlife welfare and research. Journal of Mammalogy 89: 973-990.

Clark, J. E., van Manen, F. T. and Pelton, M. R. 2002. Correlates of success for on-site release of nuisance black bears in Great Smoky Mountains National Park. Wildlife Society Bulletin 30: 104-111.

Deguchi, Y., Sato, S. and Sugawara, K. 2003. Behavior of Asiatic black bear (Ursus thibetanus) and crop damage in the forage corn field. Nihon Chikusan Gakkaiho [Animal Science Journal] 74: 383-388 (in Japanese with English abstract).

Hazumi, T. 1994. Status of Japanese black bear. International Conference on Bear Research and Management 9: 145-148.

Herrero, S. 2002. Bear Attacks: Their Causes and Avoidance. Revised ed. The Lyons Press, Guilford, Connecticut, 304 pp.

Hooge, P. N. and Eichenlaub, B. 2001. Animal movement extension to Arcview. Version 2.04 beta. Alaska Science Center-Biological Science Office, U. S. Geological Survey, Anchorage, Alaska. $<$ http://www.absc.usgs.gov/glba/gistools/index.htm $>$. Accessed 2008 Mar 2.

Huygens, O. C., van Manen, F. T., Martorello, D. A., Hayashi, H. and Ishida, J. 2004. Relationships between Asiatic black bear kills and depredation costs in Nagano Prefecture, Japan. Ursus 15: 197-202.

Huygens, O. C. and Hayashi, H. 1999. Using electric fences to reduce Asiatic black bear depredation in Nagano prefecture, central Japan. Wildlife Society Bulletin 27: 959-964.

Hydrographic and Oceanographic Department 2006. Calculation Services: the time of rise and set of sun and moon. Japan Coast Guard, Ministry of Land, Infrastructure, Transport and Tourism, Chiyoda-ku, Tokyo (in Japanese). <http://www 1.kaiho.mlit.go.jp/ KOHO/automail/sun_form3.htm\#jyouken>. Accessed 2006 Aug 18.

Japan Meteorological Agency 2007. Table of the Monthly Means and Monthly Total. Ministry of Land, Infrastructure, Transport and Tourism, Chiyoda-ku, Tokyo. <http://www.data.jma.go.jp/obd/ stats/data/en/smp/index.html >. Accessed 2008 Apr 24.

Kozakai, C., Koike, S., Yamazaki, K. and Furubayashi, K. 2008. Examination of captive Japanese black bear activity using activity sensors. Mammal Study 33: 115-119.

Larivière, S., Huot, J. and Samson, C. 1994. Daily activity patterns 
of female black bears in a northern mixed-forest environment Journal of Mammalogy 75: 613-620.

Lewis, J. S., Rachlow, J. L., Garton, E. O. and Vierling, L. A. 2007. Effects of habitat on GPS collar performance: using data screening to reduce location error. Journal of Applied Ecology 44: 663671.

Lyons, A. J. 2005. Activity patterns of urban American black bears in the San Gabriel Mountains of Southern California. Ursus 16: $255-262$.

Mano, T., Maita, K. and Kojima, S. 1990. A new type of barrel trap for capturing brown bears. Honyurui Kagaku [Mammalian science] 30: 1-10 (in Japanese with English abstract).

Matthews, S. M., Beecham, J. J., Quigley, H., Greenleaf, S. S. and Leithead, H. M. 2006. Activity patterns of American black bears in Yosemite National Park. Ursus 17: 30-40.

Mattson, D. J. 1990. Human impacts on bear habitat use. International Conference on Bear Research and Management 8: 33-56.

Moen, R., Pastor, J. and Cohen, Y. 1997. Accuracy of GPS telemetry collar locations with differential correction. Journal of Wildlife Management 61: 530-539.

Ozaki, K. and Kudo, T. 2002. Home range: its estimators and effects of autocorrelation between locations $(<$ Feature I $>$ Perspectives on the mammalian home range study by telemetry). Nihon Seitai Gakkaishi [Japanese Journal of Ecology] 52: 233-242 (in Japanese).

Peine, J. D. 2001. Nuisance bears in communities: Strategies to reduce conflicts. Human Dimensions of Wildlife 6: 223-237.
Pelton, M. R. 2003. Black Bear. In (G. A. Feldhamer, B. C. Thompson and J. A. Chapman, eds.) Wild Mammals of North America: Biology, Management and Conversation. 2nd ed., pp. 547-555. The Johns Hopkins University Press, Baltimore, Maryland.

R Development Core Team 2008. R: A language and environment for statistical computing. R Foundation for Statistical Computing, Vienna. $<$ http://www.R-project.org.>. Accessed 2008 Oct 22.

Reimchen, T. E. 1998. Nocturnal foraging behavior of black bears, Ursus americanus, on Moresby Island, British Columbia. Canadian Field-Naturalist 112: 446-450.

Sangay, T. and Vernes, K. 2008. Human-wildlife conflict in the Kingdom of Bhutan: Patterns of livestock predation by large mammalian carnivores. Biological Conservation 141: 1272 1282.

Seaman, D. E. and Powell, R. A. 1996. An evaluation of the accuracy of kernel density estimators for home range analysis. Ecology 77 : 2075-2085.

Seaman, D. E., Millspaugh, J. J., Kernohan, B. J., Brundige, G. C., Raedeke, K. J. and Gitzen, R. A. 1999. Effects of sample size on kernel home range estimates. Journal of Wildlife Management 63: 739-747.

White, G. C. and Garrot, R. A. 1990. Analysis of Wildlife RadioTracking Data. Academic Press, San Diego, California, 383 pp.

Worton, B. J. 1989. Kernel methods for estimating the utilization distribution in home-range studies. Ecology 70: 164-168.

Received 4 March 2008. Accepted 14 January 2009. 